Original research article

\title{
A first principles investigation of the effect of aluminum, gallium and indium impurities on optical properties of $\beta-\mathrm{Si}_{3} \mathrm{~N}_{4}$ structure
}

\author{
P. Narin ${ }^{\mathrm{a}, *}$, E. Kutlu ${ }^{\mathrm{a}}$, G. Atmaca ${ }^{\mathrm{a}}$, S.B. Lişesivdin ${ }^{\mathrm{a}}$, E. Özbay ${ }^{\mathrm{b}, \mathrm{c}, \mathrm{d}}$ \\ a Departmant of Physics, Faculty of Science, Gazi University, Teknikokullar, 06500 Ankara, Turkey \\ b Nanotechnology Research Center, Bilkent University, Bilkent, 06800 Ankara, Turkey \\ c Department of Physics, Bilkent University, Bilkent, 06800 Ankara, Turkey \\ d Department of Electrical and Electronics Engineering, Bilkent University, Bilkent, 06800 Ankara, Turkey
}

\section{A R T I C L E I N F O}

\section{Article history:}

Received 27 April 2017

Accepted 7 August 2017

\section{Keywords:}

$\beta-\mathrm{Si}_{3} \mathrm{~N}_{4}$

Ab initio

Optical properties

DFT

\begin{abstract}
A B S T R A C T
In this study, effects of some impurity atoms included in IIIA group such as $\mathrm{Al}, \mathrm{Ga}$, and In on the optical properties of the $\beta-\mathrm{Si}_{3} \mathrm{~N}_{4}$ structure have been discussed. The calculations were made using Density Functional Theory (DFT) in $0-15 \mathrm{eV}$ range and local density approximation (LDA) as the exchange-correlation. Using the real and the imaginary parts of the complex dielectric function, the basic optical properties of $\beta-\mathrm{Si}_{3} \mathrm{~N}_{4}$ such as dielectric coefficient, refractive index, absorption, reflection coefficients have been investigated. As a result of the calculations, it is determined that optical properties of structure have been significantly changed with doping.
\end{abstract}

(c) 2017 Elsevier GmbH. All rights reserved.

\section{Introduction}

Silicon nitride $\left(\mathrm{Si}_{3} \mathrm{~N}_{4}\right)$ due to its strong thermal, dielectric and structural properties is mostly used in electronic, optical and industrial applications [1,2]. Thanks to its thermal insulation properties, silicon nitride is used in many industrial fields such as areas of heat conduction, gas turbines, and automobile engines, at the same time it is widely used as a passivation layer in transistor applications, light emitting diodes (LEDs) and solar cells [3-7]. In addition, silicon nitride is frequently used as a gate dielectric in high electron mobility transistors (HEMTs) [8].

$\mathrm{Si}_{3} \mathrm{~N}_{4}$ crystal structure has basically well-known $\alpha$ and $\beta$ phases, as well as phases indicated by $\gamma($ or $\mathrm{c}$ ). Wherein $\alpha, \beta$, $\gamma$ are respectively indicators of trigonal, hexagonal and cubic structures. Under high temperature and high pressure, phase shifts between these crystals structures may occur [9]. While $\alpha$ and $\beta$ phases show similarities in terms of some electronic and optical properties, $\gamma$ phase can vary in terms of these characteristics. For example, in the literature, while $\alpha$ and $\beta$ phases demonstrate close bandgap values such as $\sim 4.63 \mathrm{eV}$ and 4.50-5.50, $\gamma$ phase is given as having $\sim 3.45 \mathrm{eV}$ band gap [10,11]. The property basically separating $\alpha$ and $\beta$ phases are the fact that $c$ lattice constant is about 2 times larger than $\gamma$ phase. $\beta-\mathrm{Si}_{3} \mathrm{~N}_{4}$ structure has a 14-atom unit cell, and this cell has 6 silicon and 8 nitrogen atoms and it is a structure with P6 ${ }_{3} \mathrm{~m}$ space group.

Single crystals of $\beta-\mathrm{Si}_{3} \mathrm{~N}_{4}$ structure can be grown with Molecular Beam Epitaxy (MBE) and Chemical Vapor Deposition (CVD) methods [12-14]. Generally, in GaN or GaAs-based crystal growing, Indium and Aluminum usage are common pro-

\footnotetext{
* Corresponding author.

E-mail address: polatnarin0@gmail.com (P. Narin).
} 


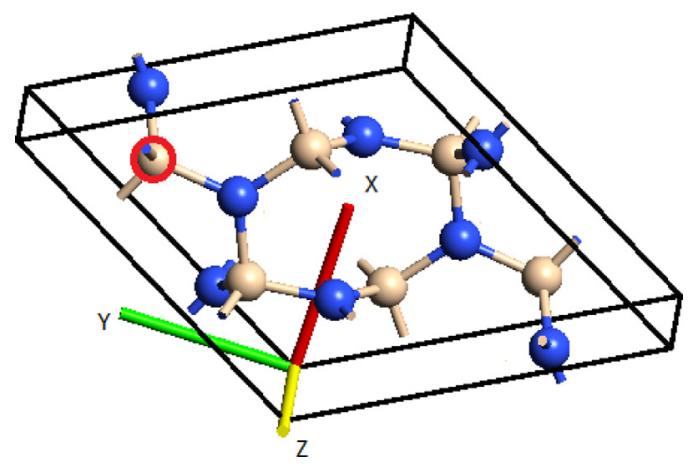

Fig. 1. The most stable atom position is shown for $\mathrm{Al}$, In and $\mathrm{Ga}$ impurities that placed in $\beta$-Si ${ }_{3} \mathrm{~N}_{4}$ crystal structure.

cesses. During these growing processes, waste gases remaining from previous growths in the reactor or atoms such as $\mathrm{Al}$, Ga, In can be found in the reactor. In a crystal growth, which will be conducted later, these atoms can settle as impurity atoms within the crystal and this situation may seriously affect optical properties of the crystal $[15,16]$.

Accordingly, it can be an important step for growing processes to be conducted in the future to analyze effects of $\mathrm{Al}, \mathrm{Ga}$ and In impurities settled within the crystal during growing process on optical properties of the crystal. For this reason, in this study, changes in optical properties of $\beta-\mathrm{Si}_{3} \mathrm{~N}_{4}$ structure were analyzed by means of DFT method in situations when it contains $\mathrm{Al}$, Ga and In impurities. As a result of these analyses, serious changes in basic optical properties of $\beta-\mathrm{Si}_{3} \mathrm{~N}_{4}$ structure were observed in terms of static dielectric constant, refractive index, absorption, reflection coefficients.

\section{Calculation method}

In calculations, to determine effects of impurity atoms such as $\mathrm{Al}$, $\mathrm{Ga}$ and In on optical properties of the $\beta-\mathrm{Si}_{3} \mathrm{~N}_{4}$ structure, DFT with pseudopotential method and LDA as exchange-correlation were used. Thanks to Atomistix-Visual Nanolab Toolkit (ATK-VNL) software, the optical properties of $\beta-\mathrm{Si}_{3} \mathrm{~N}_{4}$ structure with purity and impurity were analyzed with the help of the real and the imaginary parts of complex dielectric function [17-19]. While analyzing optical properties of the $\beta$ $-\mathrm{Si}_{3} \mathrm{~N}_{4}$ structure, a hexagonal $\beta-\mathrm{Si}_{3} \mathrm{~N}_{4}$ structure with 14 atoms containing 8 nitrogen and 6 silicon atoms and having $\mathrm{P}_{3} \mathrm{~m}$ space group was used. In calculations, lattice constants of the structure were determined as a $=7.6015 \AA, c=2.9061 \AA$, cut-off as $280 \mathrm{eV}$ and a regular Monkhorst-Pack $4 \times 4 \times 10 \mathrm{k}$-point grid were used. In the optical properties calculations, photon energy range was selected as $0-15 \mathrm{eV}$. In the studied $\beta-\mathrm{Si}_{3} \mathrm{~N}_{4}$ structure, settlement locations of $\mathrm{Al}$, In and Ga impurity atoms were determined by calculating formation energy and binding energy calculations [20]. For the atom places with the lowest formation energy and binding energy, impurity atoms were placed, and optical properties of these new systems were analyzed. By calculating binding energy and formation energy, the most stable configuration specified for each impurity atom are shown with red circle in Fig. 1.

\section{Results and discussion}

The optical properties of a studied structure can be defined with the help of the complex dielectric function given in Eq. (1) $[21,22]$. Further optical properties can be determined after obtaining real and imaginary parts of the complex dielectric function.

Complex dielectric function is given as;

$$
\varepsilon(\omega)=\varepsilon_{1}(\omega)+i \varepsilon_{2}(\omega),
$$

The real and imaginary parts of the complex dielectric function are given with the Kramers-Kronig relations;

$$
\varepsilon_{1}(\omega)=1+\frac{2}{\pi} p \int_{0}^{\infty} \frac{\omega^{\prime} \varepsilon_{2}\left(\omega^{\prime}\right)}{\omega^{\prime 2}-\omega^{2}} d \omega^{\prime} .
$$

Here, $\varepsilon_{2}(\omega)$ is the imaginary part of the complex dielectric function and given as;

$$
\varepsilon_{2}(\omega)=\frac{e_{2} h}{\pi m^{2} \omega^{2}} \sum \sum \int\left|e P_{i f}\right|^{2} \delta\left(E_{f}^{k}-E_{i}^{k}-\hbar \omega\right) d^{3} k .
$$

Here, $E_{i}$ and $E_{f}$ are binding energies in the first and the last configurations, and $P_{i f}$ is the momentum matrix element [23]. Also, $n$ and $k$ are associated with expressions $\varepsilon_{1}(\omega)$ and $\varepsilon_{2}(\omega)$ the relationship between them is given as [22];

$$
\varepsilon_{1}=n^{2}-k^{2},
$$


Table 1

Static dielectric coefficient, refractive index and reflection coefficient of $\beta-\mathrm{Si}_{3} \mathrm{~N}_{4}$ for pure and with impurities.

\begin{tabular}{llll}
\hline$\beta-\mathrm{Si}_{3} \mathrm{~N}_{4}$ & ${ }_{\varepsilon 1}(0)$ & $\mathrm{n}(0)$ & $\mathrm{R}(0)$ \\
\hline pure & 5.52 & 2.34 & 0.16 \\
Al-impurity & 9.12 & 3.59 & 0.32 \\
Ga-impurity & 122 & 11.0 & 0.70 \\
In-impurity & 75.7 & 8.70 & 0.63 \\
\hline
\end{tabular}
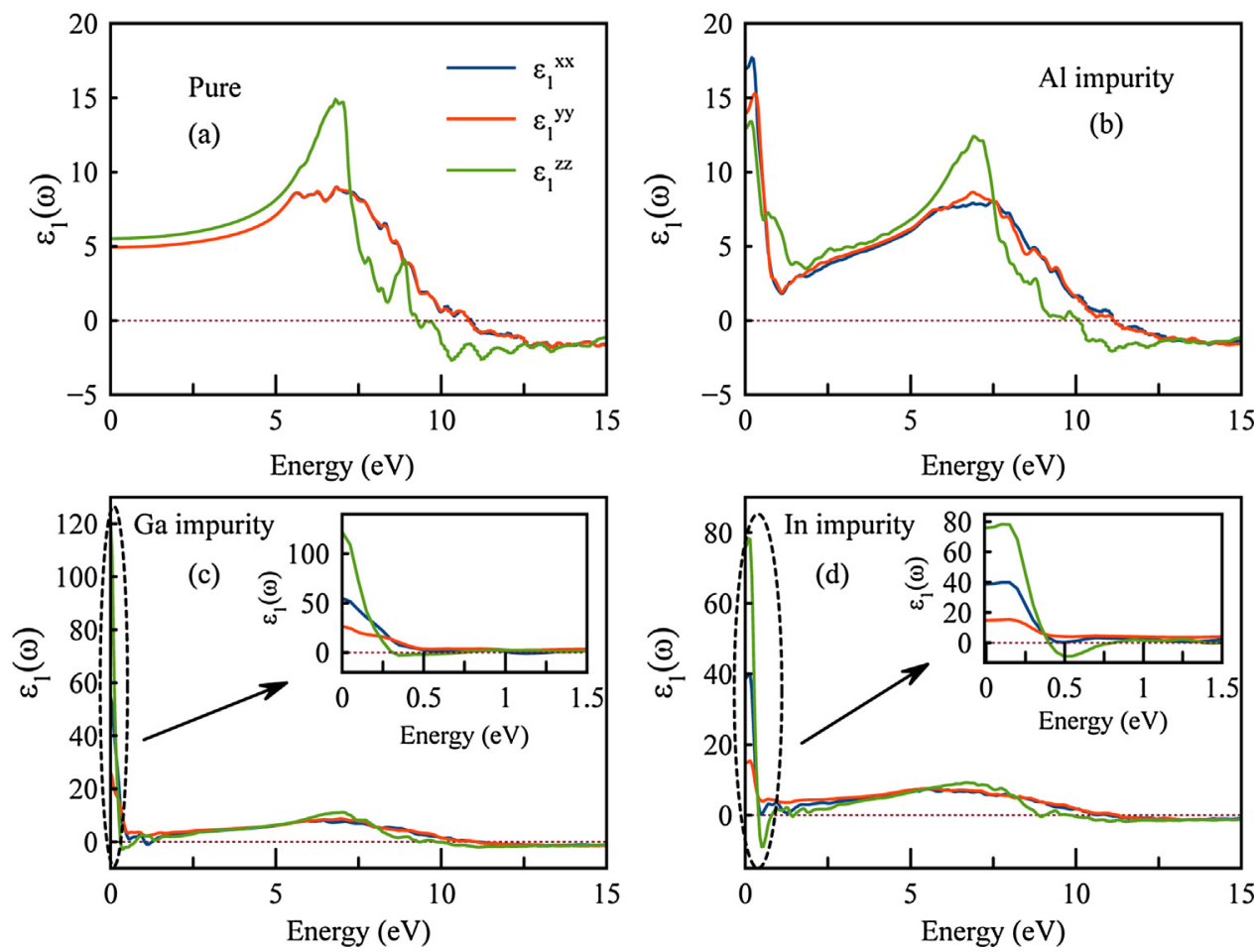

Fig. 2. For a) pure b) Al-impurity c) Ga impurity, d) In impurity added structures, the real part of the dielectric function of $\beta$-Si ${ }_{3} \mathrm{~N}_{4}$ structure.

$$
\varepsilon_{2}=2 n k
$$

Expressions giving the frequency dependent real and imaginary parts of the complex refractive index and their reflection coefficient and absorption coefficient are given as follows [24,25];

$$
\begin{aligned}
& n(\omega)=(1 / \sqrt{2})\left[\sqrt{\varepsilon_{1}^{2}(\omega)+\varepsilon_{2}^{2}(\omega)}+\varepsilon_{1}(\omega)\right]^{1 / 2}, \\
& k(\omega)=(1 / \sqrt{2})\left[\sqrt{\varepsilon_{1}^{2}(\omega)+\varepsilon_{2}^{2}(\omega)}-\varepsilon_{1}(\omega)\right]^{1 / 2}, \\
& R(\omega)=\frac{(n-1)^{2}+k^{2}}{(n+1)^{2}+k^{2}} \\
& \alpha(\omega)=2 \frac{\omega}{c} k .
\end{aligned}
$$

$\beta-\mathrm{Si}_{3} \mathrm{~N}_{4}$ structure shows anisotropic optical properties due to its hexagonal structure. Therefore, $\mathrm{z}$-axis, which corresponds to the growth direction, values with important optical features are shown in the study. Therefore, for the rest of the study, the numerical values will be given for z-axis. Table 1 shows the calculated optical parameters of $\beta-\mathrm{Si}_{3} \mathrm{~N}_{4}$ for pure and with impurities.

Fig. 2 shows the changes in photon energy dependent real part of dielectric functions after adding $\mathrm{Al}$, Ga, In impurities separately to $\beta-\mathrm{Si}_{3} \mathrm{~N}_{4}$ structure. In Fig. 2a, while highly anisotropic behavior is observed for $\mathrm{z}$-axis for pure $\beta$-Si $\mathrm{N}_{4}$ structure, it shows relatively isotropic behavior for $\mathrm{x}$ and $\mathrm{y}$-axes for the dielectric functions. For the pure $\beta$-Si $\mathrm{S}_{3} \mathrm{~N}_{4}$ structure, the static dielectric value is determined as $\sim 5.52$. 

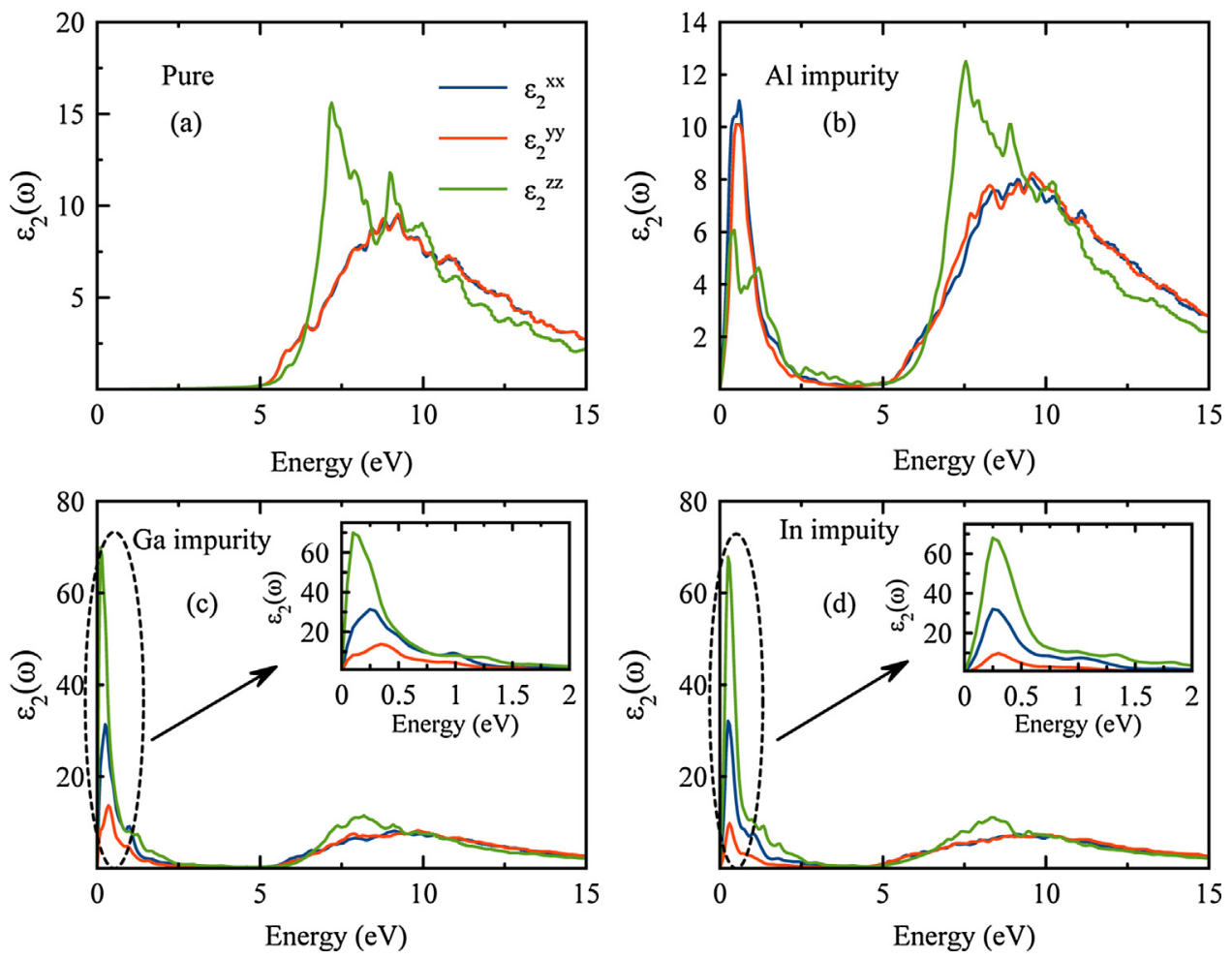

Fig. 3. For a) pure b) Al-impurity c) Ga impurity, d) In impurity added structures, the imaginary part of the dielectric function of $\beta$-Si ${ }_{3} \mathrm{~N}_{4}$ structure.

Real parts of the dielectric functions falling below zero, namely when $\varepsilon_{1}(\omega)<0$ and in energies after $9.28 \mathrm{eV}$ value, $\beta-\mathrm{Si}_{3} \mathrm{~N}_{4}$ shows metallic behavior. Within the energy range before this value, since real part of the dielectric function is above zero, namely $\varepsilon_{1}(\omega)>0$, the structure shows dielectric properties.

In Fig. $2 b$, it was determined that the static dielectric constant for $\beta-\mathrm{Si}_{3} \mathrm{~N}_{4}$ structure containing $\mathrm{Al}$ impurity is 9.12 , and the highest value for the dielectric constant as 13.4 is found at $\sim 0.19 \mathrm{eV}$ value. While isotropic behavior in $\mathrm{x}$ and $\mathrm{y}$-axes is not observed below $0.4 \mathrm{eV}$, it can be seen that isotropic behavior is started again while approaching towards high energies. As expected in all energy values, the high anisotropic behavior is observed in the z-axis. In Fig. $2 c$, for a $\beta-\mathrm{Si}_{3} \mathrm{~N}_{4}$ structure containing Ga impurity, the static dielectric value is found as a huge number of 122 . A static dielectric constant substantially higher than the pure structure has been calculated.

In Fig. 2d, we have calculated static dielectric constant for $\beta-\mathrm{Si}_{3} \mathrm{~N}_{4}$ containing In impurity as 75.7 . The highest dielectric constant was determined as 78.3 at $0.1 \mathrm{eV}$ value. While isotropic behavior in $\mathrm{x}$ and $\mathrm{y}$-axis is observed in low energy values, the anisotropic behavior is seen at high energy values. In this regard, it can be said that, this behavior exhibits similar characteristics with the structure including Ga impurity.

In Fig. 3, imaginary parts of dielectric function based on photon energy are shown for the pure $\beta-\mathrm{Si}_{3} \mathrm{~N}_{4}$ structure and structures with impurities within $0-15 \mathrm{eV}$ energy range. In Fig. 3a, it can be seen that optical band range value for pure $\beta-\mathrm{Si}_{3} \mathrm{~N}_{4}$ is within $\sim 5-5.8 \mathrm{eV}$ range. The optical band value of the pure $\beta-\mathrm{Si}_{3} \mathrm{~N}_{4}$ structure is consistent with the literature $[10,26,27]$. Energy values where optical transitions are at maximum are seen as $7.2 \mathrm{eV}$ and $9 \mathrm{eV}$. In the cases with impurities, it can be clearly seen that structures $\varepsilon_{2}(\omega)$ peak values at very low energies do not represent any optical band gap.

In Fig. $3 \mathrm{~b}$, it can be seen that in $\beta-\mathrm{Si}_{3} \mathrm{~N}_{4}$ structure with $\mathrm{A} 1$ impurity, energy values with maximum optical transitions are $7.5 \mathrm{eV}$ and $9 \mathrm{eV}$. Furthermore, since it is observed that optical transition also occurs in $\sim 0.45 \mathrm{eV}$ and $\sim 1.19$ energy values, it will not be possible to mention about optical band range in A1 impurity. In comparison with the pure structure, for $\mathrm{x}$ and $\mathrm{y}$-axes, the isotropic behavior is partially deteriorated.

In Fig. 3c and 3d respectively, it can be seen that very high optical transitions occur at very low energies in $\beta-\mathrm{Si}_{3} \mathrm{~N}_{4}$ structure with $\mathrm{Ga}$ and In impurities. In the presence of both impurities, a secondary peak with not such high optical transitions can be observed at $\sim 8 \mathrm{eV}$. For these two impurity added structures, highly anisotropic behavior at low energy values and isotropic behavior at high energy values are observed.

In Fig. 4, changes in refractive indexes of pure $\beta-\mathrm{Si}_{3} \mathrm{~N}_{4}$ structure and structure with impurities are given with respect to photon energy. These changes can be actually seen to change in proportion to change connected with $\varepsilon_{1}(\omega)$ in the formula given Eq. (4). Therefore, if the dielectric coefficient of a structure is high, it's refractive index is high as well. In the pure $\beta-\mathrm{Si}_{3} \mathrm{~N}_{4}$ structure, the refractive index of the structure was determined as $\mathrm{n}(0)=2.34$ and results closer to the literature was obtained [28,29]. In structures with $\mathrm{Al}, \mathrm{Ga}$ and In impurities, refractive indexes were determined as 3.59, was 11 and 

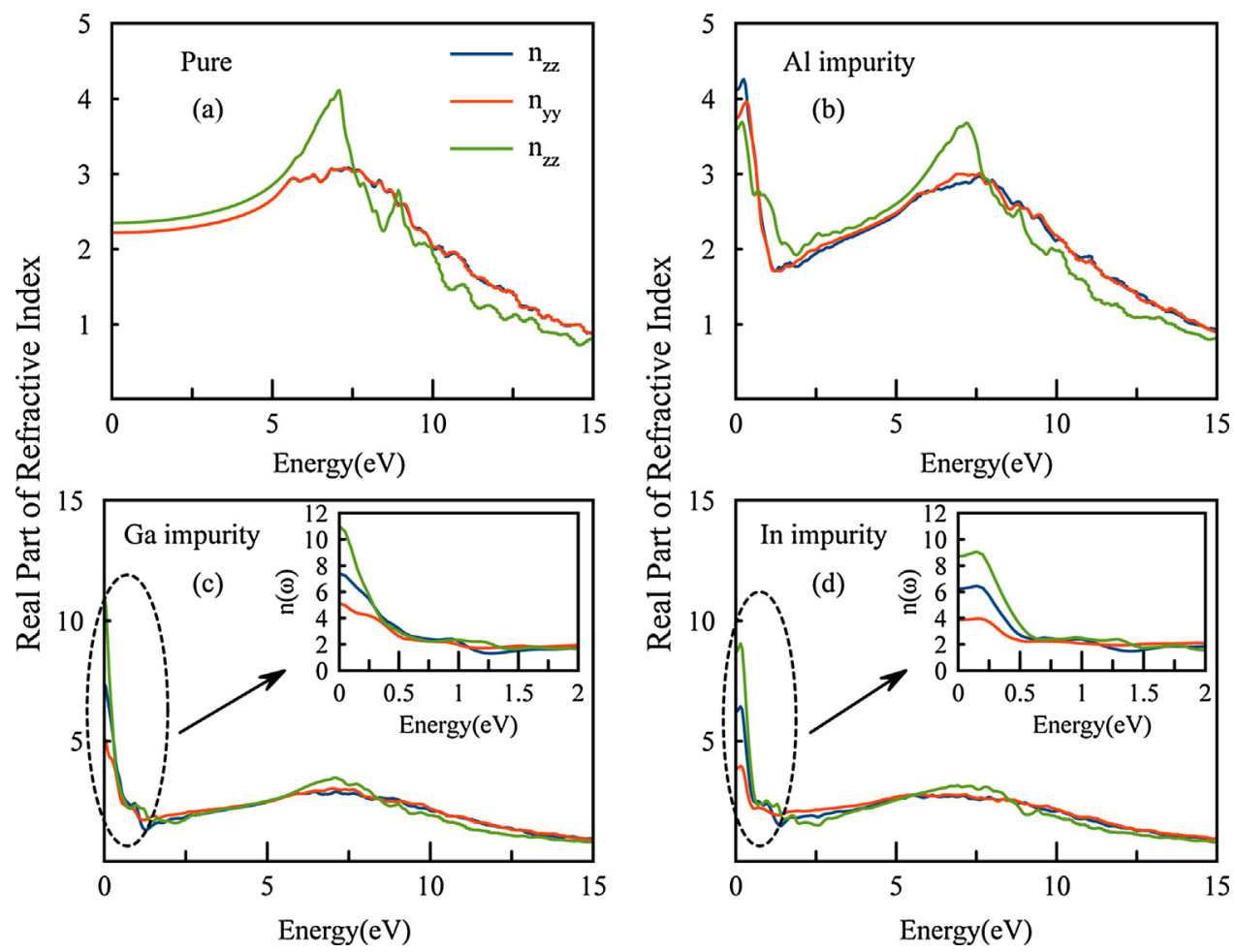

Fig. 4. For a) pure b) Al-impurity c) Ga impurity, d) In impurity, the refractive index of $\beta-\mathrm{Si}_{3} \mathrm{~N}_{4}$ structure.

8.7, respectively. The structure with Ga-impurity has the highest refractive index, which is found to be 5 times higher than the pure structure. It is observed that refractive index change showing high anisotropic behavior along the z-axis in pure structure and the structure with Al impurity. For the structures with Ga and In impurities, mostly isotropic behavior are observed at higher energies. However, high anisotropic behaviors are observed at very low energies.

The imaginary part of the complex refractive index, namely extinction coefficient is known to be associated with $\varepsilon_{2}(\omega)$ given by the Eq. (5). Therefore, change in photon frequency dependent $\varepsilon_{2}(\omega)$ and change in photon frequency dependent extinction coefficient are shown similar behaviors. Changes in photon frequency dependent extinction coefficients of pure $\beta-\mathrm{Si}_{3} \mathrm{~N}_{4}$ structure and structures with impurities are given in Fig. 5. Since it is dielectric in the pure structure, it is observed that optical transitions start around above $\sim 5 \mathrm{eV}$. In the structures with $\mathrm{Al}, \mathrm{Ga}$ and In impurities, the higher extinction coefficient is observed at lower energies. Anisotropy behaviors are similar with the real part of the complex refractive index.

Reflectance properties of structure vary in connection with whether they show metallic behavior or not. Since $\varepsilon_{1}(\omega)<0$ is considered structures with metallic behavior, negative $\varepsilon_{1}(\omega)$ represents high reflectivity. For negative values of $\varepsilon_{1}(\omega)$ are found to be possible with Eq. (4) and $k>n$. Therefore, high level of reflectance is expected for low $n$ and high $k$ values.

In Fig. 6, changes in reflectance of pure $\beta-\mathrm{Si}_{3} \mathrm{~N}_{4}$ structure and structures with impurities are given with respect to photon energy. For pure $\beta-\mathrm{Si}_{3} \mathrm{~N}_{4}$ and $\beta-\mathrm{Si}_{3} \mathrm{~N}_{4}$ with $\mathrm{Al}, \mathrm{Ga}$, In impurities, reflection coefficients of structures are determined as 0.16 , $0.32,0.70$ and 0.63 , respectively. For the structures with impurities, behaviors of reflectance with energy changes show similarities with each other.

At values where extinction coefficient is high, it can be expected absorption coefficient to be high also. In Fig. 7, absorption data shows the optical band gap successfully. In the structures with impurities, the anisotropic behavior is preserved in the $\mathrm{z}$-axis all along the investigated photon energies. Near the optical band-gap edge, pure $\beta-\mathrm{Si}_{3} \mathrm{~N}_{4}$ structure shows the most anisotropic behavior.

$\mathrm{Si}_{3} \mathrm{~N}_{4}$ is known to reduce non-radiative transitions in the structure where it is used as a passivation layer [30]. In addition, in cases where the passivation layer contains impurities since more absorption occurs as can be seen in Fig. 8. Using $\mathrm{Si}_{3} \mathrm{~N}_{4}$ as much pure as possible becomes significant especially in LED applications. Fig. 8 shows absorption for pure structure and structures with $\mathrm{Al}$, Ga, In impurities that change at low energies, especially in the visible region. While very low absorption is observed in the visible region for the pure with impurities structures, especially the structure with In impurity shows very high absorption in the visible region. 

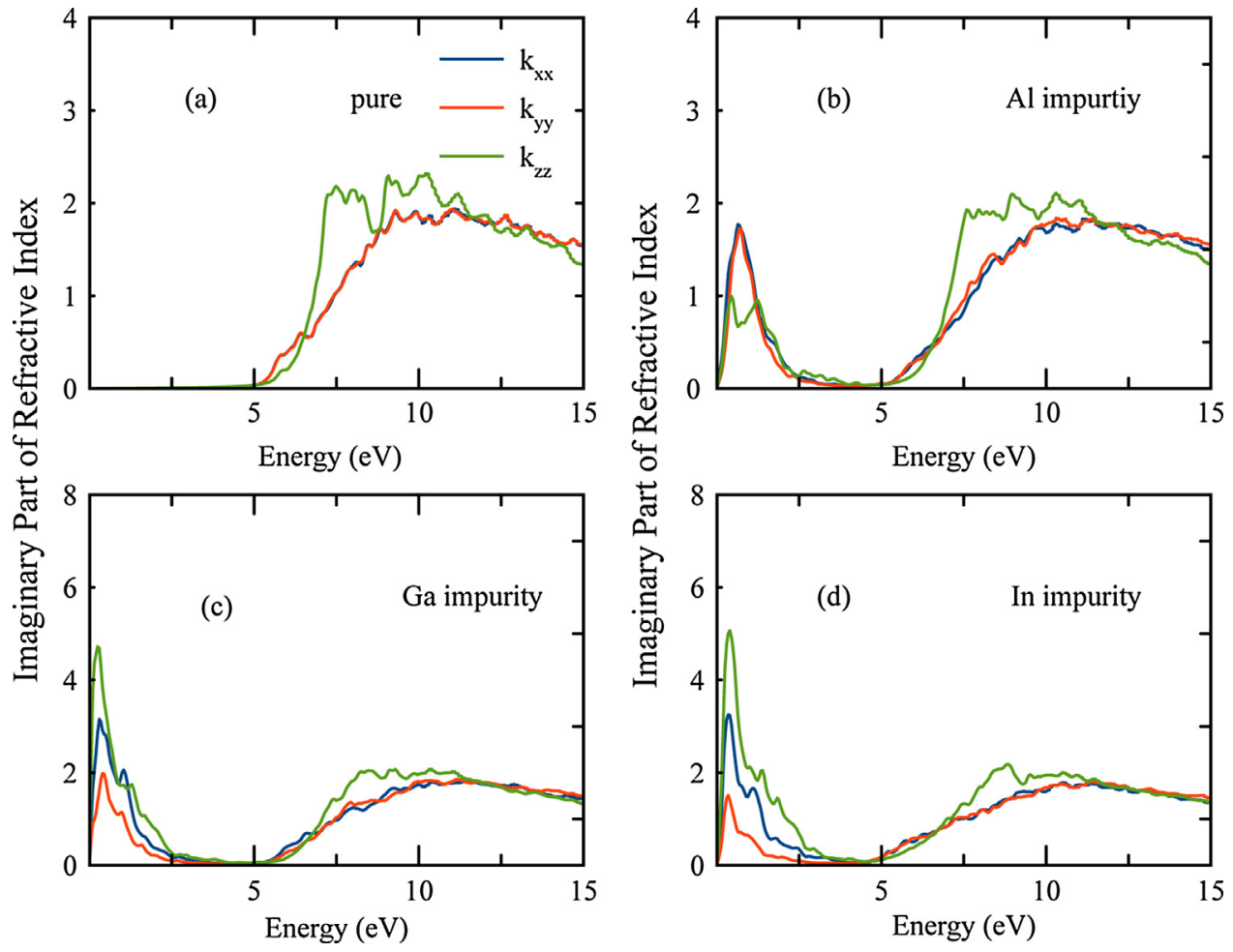

Fig. 5. For a) pure b) Al-impurity c) Ga impurity, d) In impurity added structures, the extinction coefficient of $\beta-\mathrm{Si}_{3} \mathrm{~N}_{4}$ structure.
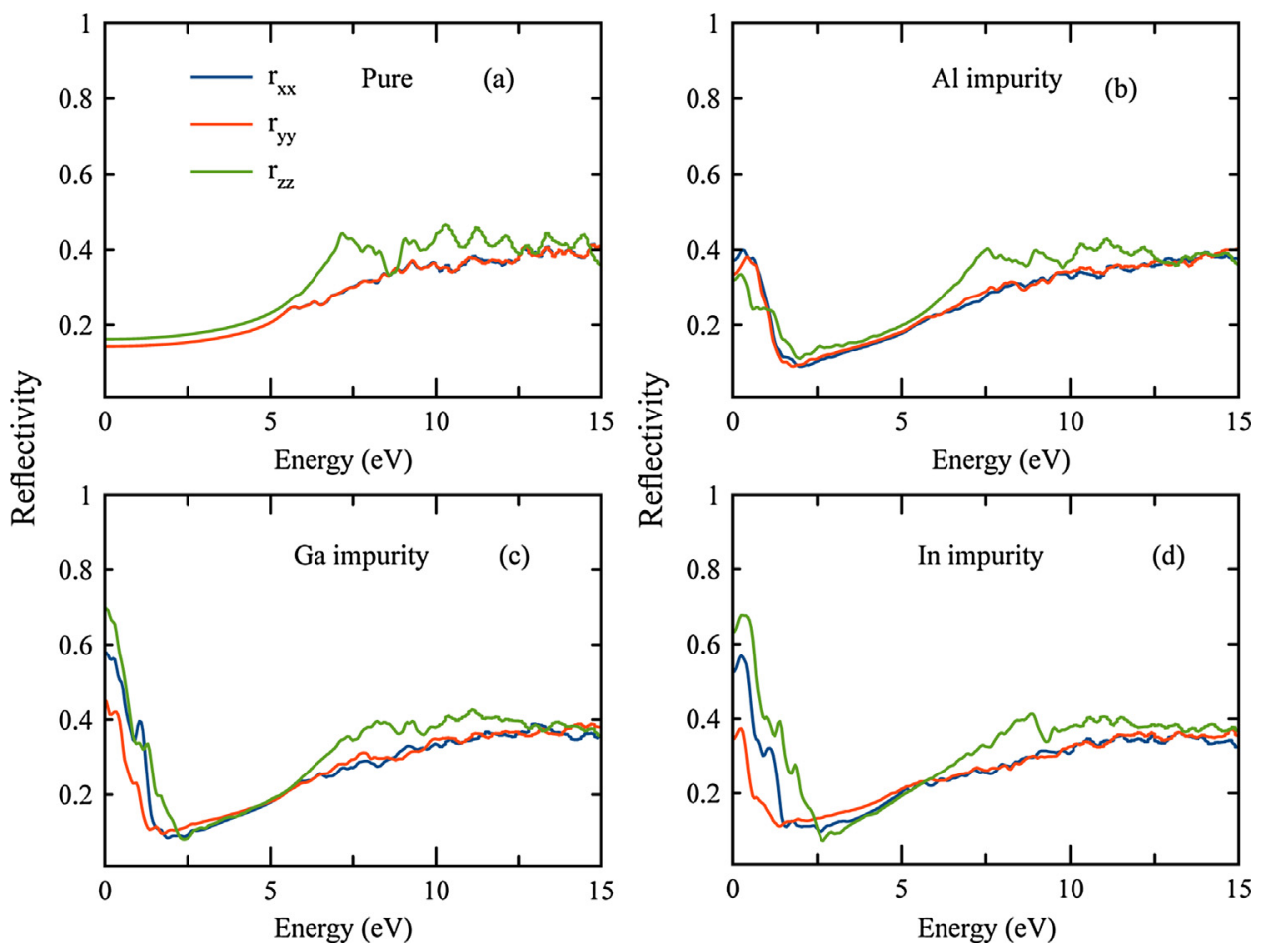

Fig. 6. For a) pure and b) Al-impurity c) Ga impurity, d) In impurity added structures, the reflection coefficient of $\beta-\mathrm{Si}_{3} \mathrm{~N}_{4}$ structure. 

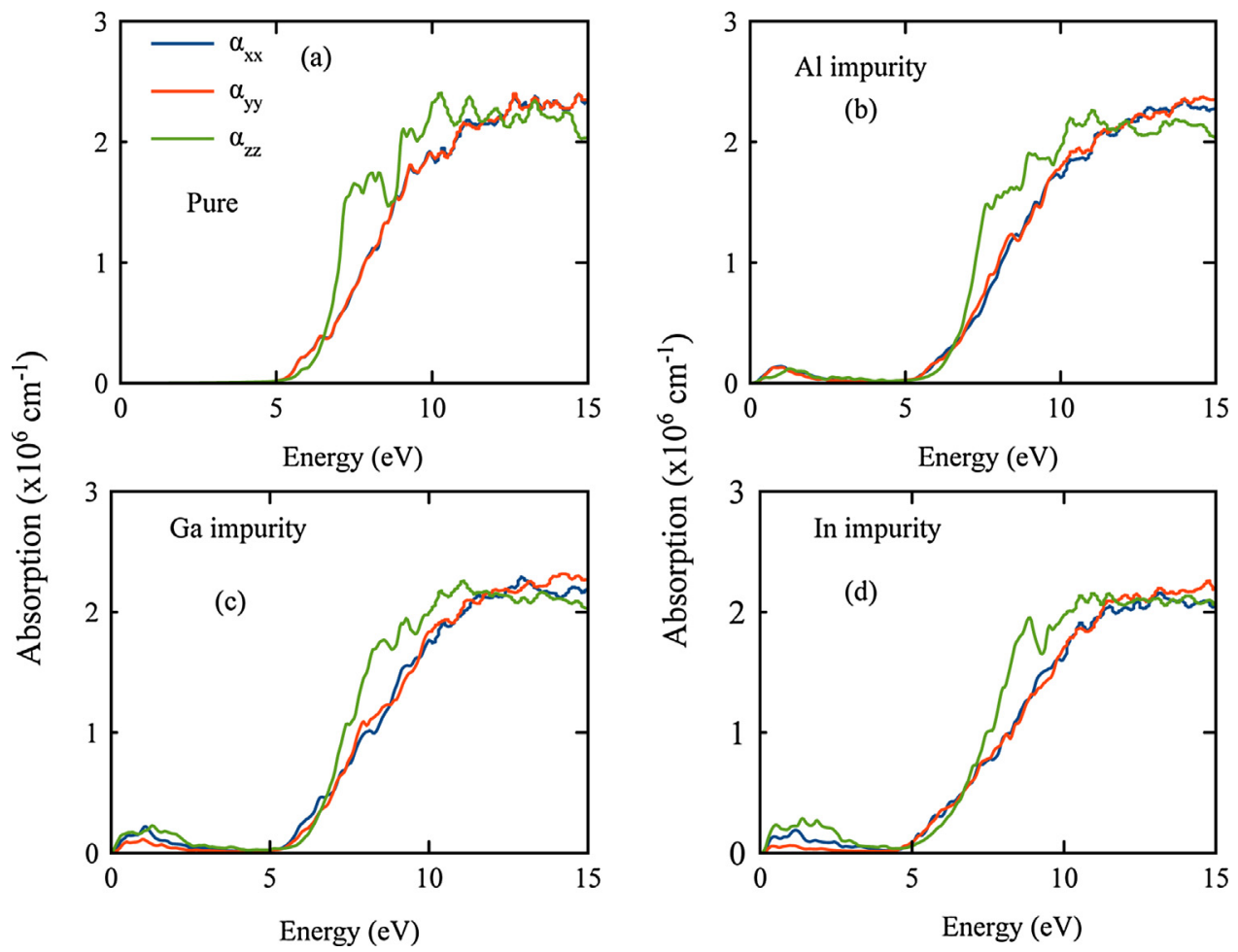

Fig. 7. For a) pure b) Al-impurity c) Ga impurity, d) In impurity added structures, the absorption coefficient of $\beta-\mathrm{Si}_{3} \mathrm{~N}_{4}$ structure.

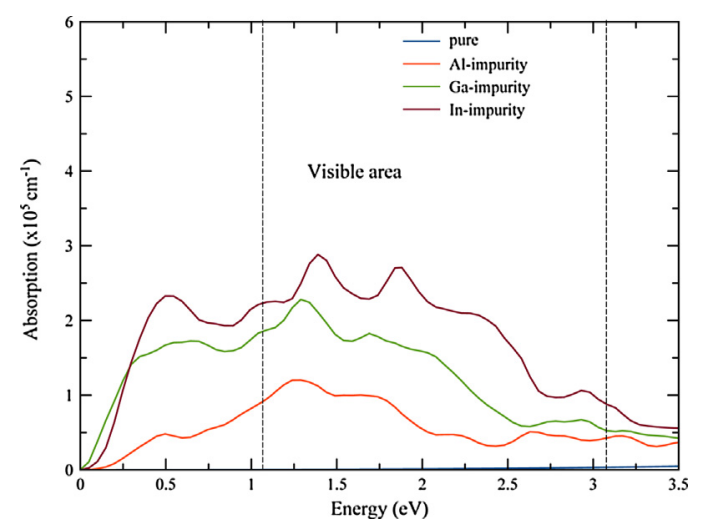

Fig. 8. For a) pure, b) As-impurity, c) Ga impurity, d) In impurity added structures, absorption of $\beta-\mathrm{Si}_{3} \mathrm{~N}_{4}$ structures at low energies.

\section{Conclusion}

In this study, the effects of impurity atoms such as $\mathrm{Al}, \mathrm{Ga}$, and In found in IIIA group of the periodic table, on optical properties of pure $\beta-\mathrm{Si}_{3} \mathrm{~N}_{4}$ structure were analyzed. The calculations were performed with DFT method using LDA approach within 0-15 eV range. Based on impurity atoms, the changes in basic optical properties of $\beta-\mathrm{Si}_{3} \mathrm{~N}_{4}$ structure such as complex dielectric function, refractive index, extinction coefficient, absorption coefficient, reflection coefficient based on photon energy were analyzed. As a result of calculations, static dielectric coefficients were found for pure $\beta-\mathrm{Si}_{3} \mathrm{~N}_{4}$ and structures with impurities, and it was observed that impurity atoms increase the dielectric constant to relatively higher values. It is determined that, in the pure $\beta-\mathrm{Si}_{3} \mathrm{~N}_{4}$ structure, isotropic optical properties that are observed mostly between $\mathrm{x}$ and $\mathrm{y}$ axes. And with adding impurities this behavior tends towards anisotropic behavior. As expected in hexagonal crystals, it presents high anisotropic optical properties in z-axis with respect to other axes. Due to the increasing absorption at visible wavelengths, impurities may result in unwanted outcomes in optoelectronic devices such as LEDs. 


\section{Acknowledgement}

This work is supported by the projects DPT-HAMIT, DPT-FOTON, and NATO-SET-193 as well as TUBITAK under Project Nos. 113E331, 109A015, and 109E301. One of the authors (Ekmel Ozbay) also acknowledges partial support from the Turkish Academy of Sciences.

\section{References}

[1] B. Wang, J. Yang, R. Guo, J. Gao, J. Yang, Microstructure and property enhancement of silicon nitride-barium aluminum silicate composites with B-Si3N4 seed addition, J. Mater. Sci. 44 (2009) 1351-1356.

[2] J.H. Kim, K.W. Chung, Microstructure and properties of silicon nitride thin films deposited by reactive bias magnetron sputtering, J. Appl. Phys. 83 (1998) 5831-5839.

[3] S.Y. Ren, W.Y. Ching, Electronic structures of $\beta$-and $\alpha$-silicon nitride, Phys. Rev. B 23 (1981) 5454-5463.

[4] A.Y. Liu, M.L. Cohen, Structural properties and electronic structure of low-compressibility materials: $\beta-\mathrm{Si}_{3} \mathrm{~N}_{4}$ and hypothetical $\beta-C_{3} \mathrm{~N}_{4}$, Phys. Rev. $\mathrm{B}$ 41 (1990) 10727-10734.

[5] X. Hu, A. Koudymov, G. Simin, J. Yang, M.A. Khan, A. Tarakji, R. Gaska, $\mathrm{Si}_{3} \mathrm{~N}_{4} / \mathrm{AlGaN} / \mathrm{GaN}$-metal-insulator-semiconductor heterostructure field-effect transistors, Appl. Phys. Lett. 79 (2001) 2832-2834.

[6] M. Meneghini, L.R. Trevisanello, U. Zehnder, T. Zahner, U. Strauss, G. Meneghesso, E. Zanoni, High-temperature degradation of GaN LEDs related to passivation, electron devices, IEEE Trans. 53 (2006) 2981-2987.

[7] Y. Ogawa, K. Ohdaira, T. Oyaidu, H. Matsumura, Protection of organic light-emitting diodes over 50000 hours by Cat-CVD $\mathrm{SiN}_{\mathrm{x}} / \mathrm{SiO}_{\mathrm{x}} \mathrm{N}_{\mathrm{y}} \mathrm{stacked}$ thin films, Thin Solid Films 516 (2008) 611-614.

[8] G. Kresse, M. Marsman, L.E. Hintzsche, E. Flage-Larsen, Optical and electronic properties of $\mathrm{Si}_{3} \mathrm{~N}_{4}$ and $\alpha-\mathrm{SiO}_{2}$, Phys. Rev. B 85 (2012) 0405205-0405212.

[9] B. Wang, J. Yang, R. Guo, J. Gao, J. Yang, Microstructure and boundary phases of Lu-Al-doped silicon nitride by pressureless sintering, Mater. Sci. Eng.: A 500 (2009) 79-83.

[10] Y.N. Xu, W.Y. Ching, Electronic structure and optical properties of $\alpha$ and $\beta$ phases of silicon nitride, silicon oxynitride and with comparison to silicon dioxide, Phys. Rev. B 51 (1995) 17379-17389.

[11] Y.C. Ding, A.P. Xiang, M. Xu, W.J. Zhu, Electronic structures and optical properties of $\gamma$-Si 3 N 4 doped with La, Physica B: Condens. Matter 403 (2008) 2200-2206

[12] B. Stannowski, J.K. Rath, R.E.I. Schropp, Growth process and properties of silicon nitride deposited by hot-wire chemical vapor deposition, J. Appl. Phys. 93 (2003) 2618-2625.

[13] G. Lucovsky, P.D. Richard, D.V. Tsu, S.Y. Lin, R.J. Markunas, Deposition of silicon dioxide and silicon nitride by remote plasma enhanced chemical vapor deposition, J. Vacuum Sci. Technol. A 4 (1986) 681-688.

[14] Y. Nakada, I. Aksenov, H. Okumura, GaN heteroepitaxial growth on silicon nitride buffer layers formed on Si (111) surfaces by plasma-assisted molecular beam epitaxy, Appl. Phys. Lett. 73 (1998) 827-829.

[15] Y.X. Han, C.L. Yang, M.S. Wang, X.G. Ma, Tuning the band gap and optical properties of $\gamma$ - $\mathrm{Si}_{3} \mathrm{~N}_{4}$ with rare earth element Ce, RSC Adv. 4 (2014) $55452-55458$

[16] E. Kutlu, P. Narin, G. Atmaca, B. Sarikavak-Lisesivdin, S.B. Lisesivdin, E. Ozbay, Effect of substitutional As impurity on electrical and optical properties of $\beta$-Si 3 N 4 structure, Mater. Res. Bull. 83 (2016) 128-134.

[17] Version 12.2.2 QuantumWise A/S. <http://www.quantumwise.com>.

[18] M. Brandbyge, J.L. Mozos, J.Taylor P.Ordejón, K. Stokbro, Density-functional method for nonequilibrium electron transport, Phys. Rev. B 65 (2002) $165401-165418$

[19] E. Kutlu, P. Narin, G. Atmaca, B. Sarikavak-Lisesivdin, S.B. Lisesivdin, E. Ozbay, Electronic structure of $\beta-\mathrm{Si}_{3} \mathrm{~N}_{4}$ crystals with substitutional icosagen group impurities, J. Optoelectron. Adv. Mater. 19 (2017) 278-282.

[20] J.M. Soler, E. Artacho, J.D. Gale, A. Garclá, J. Junquera, P. Ordejón, D. Sánchez-Portal, The SIESTA method for ab initio order-N materials simulation, J. Phys. Condens. Matter 14 (2002) 2745-2779.

[21] H. Ehrenreich, H.R. Philipp, Optical properties of Ag and Cu, Phys. Rev. 128 (1962) 1622-1629.

[22] Y. Du, B. Chang, X. Fu, X. Wang, Meishan Wang, Electronic structure and optical properties of zinc-blende GaN, Optik 123 (2012) $2208-2212$.

[23] F. Wooten, Optical Properties of Solids, Academic Press, New York, 1972.

[24] X. Yu, C. Li, Y. Ling, T.A. Tang, Q. Wu, J. Kong, First principles calculations of electronic and optical properties of Mo-doped rutile TiO2, J. Alloys Compd. 507 (2010) 33-37.

[25] Y. Shen, Z. Zhou, Structural, electronic and optical properties of ferroelectric KTa $\mathrm{T}_{1 / 2} \mathrm{Nb}_{1 / 2} \mathrm{O}$ solid solutions, J. Appl. Phys. 103 (2008) 074113-074120.

[26] J. F. Nye, Clarendon Press, Oxford (1957) p. 297.

[27] H. Kurata, M. Hirose, Y. Osaka, Wide optical-gap photoconductive a-SixN1-x:H, Jpn. J. Appl. Phys. 20 (1981) L811.

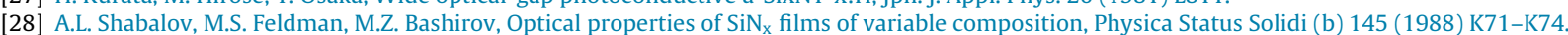

[29] R.W. Knoll, C.H. Henager Jr., Optical and physical properties of sputtered Si:Al:O:N films, J. Mater. Res. 7 (1992) 1247-1252.

[30] S. Jahangir, M. Mandl, M. Strassburg, P. Bhattacharya, Molecular beam epitaxial growth and optical properties of red-emitting $(\lambda=650 \mathrm{~nm})$ InGaN/GaN disks-in-nanowires on silicon, Appl. Phys. Lett. 102 (2013) 071101 